\title{
Management of limited joint mobility in diabetic patients
}

This article was published in the following Dove Press journal:

Diabetes, Metabolic Syndrome and Obesity:Targets and Therapy 6 May 2013

Number of times this article has been viewed

\section{Michele Abate' \\ Cosima Schiavone' \\ Vincenzo Salini' \\ Isabel Andia ${ }^{2}$}

'Department of Medicine and Science of Aging, University G d'Annunzio, Chieti-Pescara, Italy; ${ }^{2}$ BioCruces Health Research Institute, Cruces University Hospital, Barakaldo, Spain
Correspondence: Michele Abate Department of Medicine and Science of Aging, University G d'Annunzio, Chieti-Pescara, Via dei Vestini 3I, 66013 Chieti Scalo, Italy Tel +39 087I 358576

Fax +39 087I 358969

Email m.abate@unich.it

\begin{abstract}
Several rheumatologic manifestations are more pronounced in subjects with diabetes, ie, frozen shoulder, rotator cuff tears, Dupuytren's contracture, trigger finger, cheiroarthropathy in the upper limb, and Achilles tendinopathy and plantar fasciitis in the lower limb. These conditions can limit the range of motion of the affected joint, thereby impairing function and ability to perform activities of daily living. This review provides a short description of diabetes-related joint diseases, the specific pathogenetic mechanisms involved, and the role of inflammation, overuse, and genetics, each of which activates a complex sequence of biochemical alterations. Diabetes is a causative factor in tendon diseases and amplifies the damage induced by other agents as well. According to an accepted hypothesis, damaged joint tissue in diabetes is caused by an excess of advanced glycation end products, which forms covalent cross-links within collagen fibers and alters their structure and function. Moreover, they interact with a variety of cell surface receptors, activating a number of effects, including pro-oxidant and proinflammatory events. Adiposity and advanced age, commonly associated with type 2 diabetes mellitus, are further pathogenetic factors. Prevention and strict control of this metabolic disorder is essential, because it has been demonstrated that limited joint motion is related to duration of the disease and hyperglycemia. Several treatments are used in clinical practice, but their mechanisms of action are not completely understood, and their efficacy is also debated.
\end{abstract}

Keywords: diabetes mellitus, joint mobility, diabetic complication, tendon

\section{Introduction}

Epidemiologic studies have shown that the prevalence of several rheumatologic manifestations is increased in subjects with diabetes mellitus. ${ }^{1-3}$ Frozen shoulder, rotator cuff tears, Dupuytren's contracture, trigger finger, and cheiroarthropathy are among the most common diseases in the upper limb. Significant damage to the Achilles tendon, including plantar fasciitis in the lower leg, has been observed, and results in reduced ankle motion and onset of diabetic foot ulcers. Common symptoms include pain, swelling, and stiffness, can limit the range of motion of the affected joint, thereby impairing function and ability to perform activities of daily living. ${ }^{4-6}$ This review assesses the pathogenetic mechanisms in subjects with diabetes, as well as the onset of joint disorders, and describes current treatment strategies to improve limited joint movement. Some authors use the term "limited joint movement", referring exclusively to diabetic cheiroarthropathy, which is the most frequent joint-related disease of diabetes; however, we will use the term more extensively, referring to the abovementioned diseases, which show a compelling correlation with diabetes. 


\section{Symptomatology and epidemiology}

Tables $1-3^{7-45}$ show the main clinical features of the joint diseases associated with diabetes, and the prevalence of data in these subjects compared with the general population. The peculiar and significant clinical characteristics of these conditions are outlined. Figures 1 and 2 indicate tendon abnormalities in the upper limb (shoulder and hand), and Figure 3 shows abnormalities in the lower limb (plantar fasciitis and Achilles tendon), with ultrasound evaluation, which is currently used for the diagnosis of tendon disorders.

\section{Pathogenesis}

\section{General pathophysiologic mechanisms}

Several pathophysiologic mechanisms appear to be involved in the development of these conditions, including overuse, inflammation, trauma, mechanical impingement, and

Table I Shoulder diabetes-related diseases

\begin{tabular}{l}
\hline Frozen shoulder \\
Clinical features \\
Painful condition with restriction of shoulder ROM. \\
Classified as "idiopathic" (etiology unknown) or "secondary" \\
(to trauma, cardiovascular diseases, hemiparesis). ${ }^{7.8}$ \\
Evolution involves three overlapping phases \\
- Months 2-9: progressive stiffening and loss of motion with \\
increasing pain on movement; \\
- Months 4-12: gradual decrease in pain while stiffness aggravates; \\
- Months I2-42: resolution phase, with improvement in ROM. \\
Complete resolution in about $60 \%$ of cases, while $35 \%$ of patients \\
complain mild to moderate symptoms, and $5 \%$ severe symptoms. \\
Epidemiology \\
$5 \%-30 \%$ in subjects with diabetes versus $2 \%-5 \%$ in normal population. ${ }^{9-11}$ \\
In diabetes mellitus: worse at onset (more pain and restricted ROM), \\
more persistent and difficult to treat. Calcifications frequently \\
associated. ${ }^{.2}$ \\
Positive correlation with the duration of diabetes (the relationship \\
with age, and poor glycemic control is debated). ${ }^{10,13-15}$ \\
Possible association of frozen shoulder with Dupuytren's disease and \\
cheiroarthropathy. ${ }^{16}$
\end{tabular}

\section{Rotator cuff tears}

Clinical features

Tears can be partial or full thickness.

Supraspinatus tendon usually involved; lesions of biceps and infraspinatus tendon less common. ${ }^{17,18}$

Subacromial deltoid bursitis frequently associated. ${ }^{17}$

Limitation of shoulder motion mainly in forward elevation, internal and external rotation. $7,9,19$

\section{Epidemiology}

General population: prevalence increases with age (from $0 \%-15 \%$ in the 60 s to $30 \%-50 \%$ in the 80 s). ${ }^{20-22}$

Subjects with diabetes: prevalence fivefold higher than in the general population. . $^{4,18}$

After surgical repair: incidence of re-tears and restricted shoulder ROM higher in diabetes. ${ }^{23,24}$
Table 2 Hand diabetes-related diseases

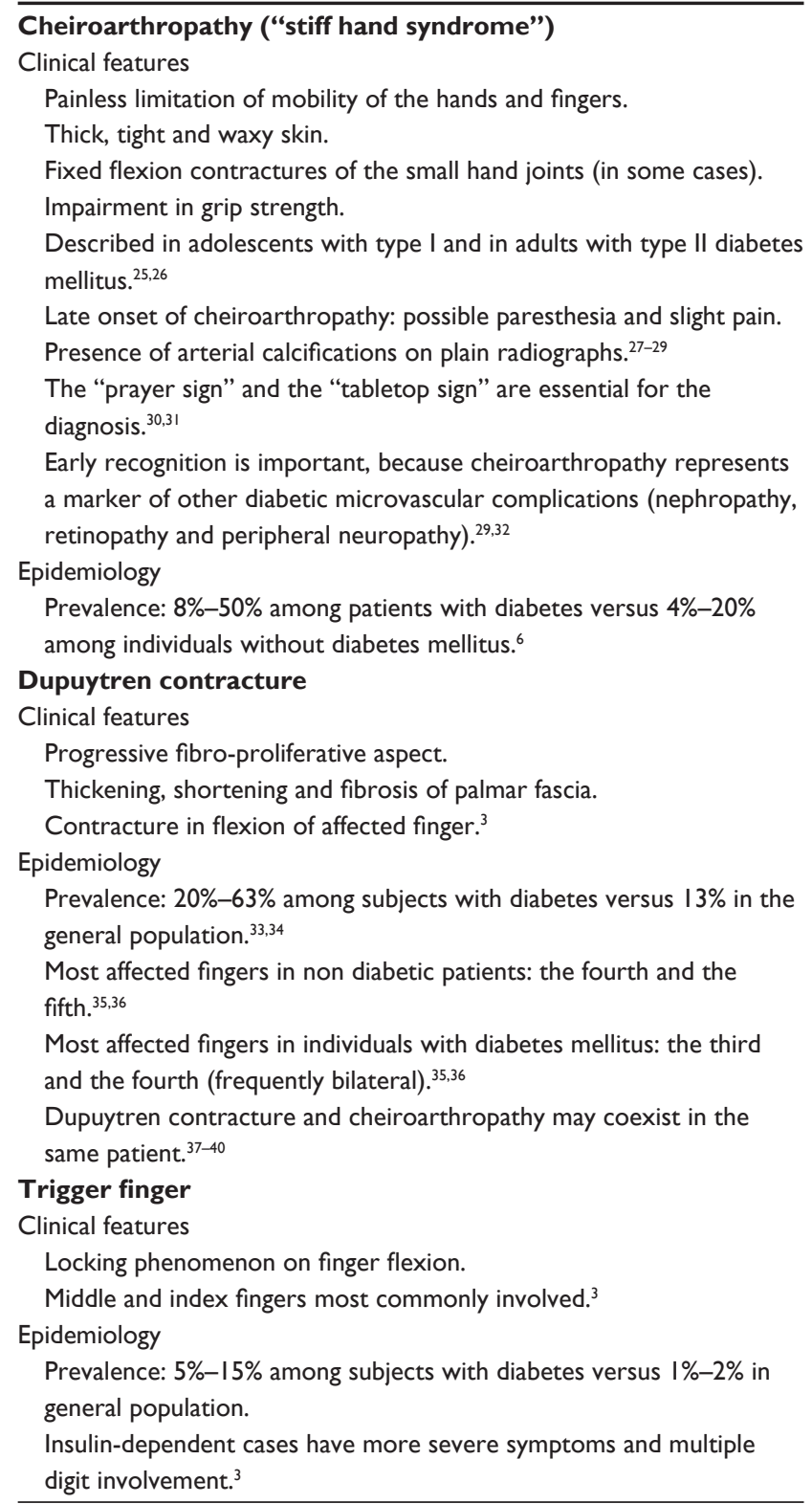

genetics, as well as immunologic, biochemical, and endocrine alterations. Their role and relevance are variable, with subjects being differentially affected by the same disease, notably in its early and late stages.

Inflammation plays a major role in adhesive capsulitis of the shoulder, and this is reflected in increased levels of inflammatory and fibrogenic cytokines in the synovium and subacromial bursa. ${ }^{18,46}$ Accordingly, in the early stages, histology shows new blood vessels in the synovial membrane and the presence of inflammatory cells, which typically progress to increased fibroblast density and myofibroblasts within a stiff collagenous matrix, explaining the clinical finding of capsular contracture. 
Table 3 Lower limb diabetes-related diseases

\section{Reduced ankle ROM}

\section{Clinical features}

Plantar fascia and Achilles tendon

Increased thickness in subjects suffering from type I and type II diabetes mellitus. ${ }^{41,42}$

More frequent in diabetic patients with neuropathy and previous foot ulcers. ${ }^{43-45}$

Thickness may be also increased in type II diabetic patients free from complications.

Thickness correlates positively with BMI. ${ }^{46}$

Involvement of Achilles tendon and plantar fascia is associated to reduced ankle joint ROM.

Limited ankle ROM may restrain the forward progression of the tibia on the fixed foot during the stance phase of walking. This, in turn, results in prolonged and excessive weight bearing stress under the metatarsal heads during the foot-floor interaction, which is thought to contribute to the development of foot ulcers in individuals with diabetes mellitus. $^{44,47}$

Abbreviations: ROM, range of movement; BMI, body mass index.

Rotator cuff tendinopathy shows degenerative changes, such as collagen degradation, increased ground substance levels, disruption of fibers, necrotic areas, hypercellularity or hypocellularity, and tears, which usually present without histologic features of inflammation. The more common causative factors include trauma, aging or reduced blood flow, and acromial spur impingement. ${ }^{17}$

In Dupuytren's contracture, histopathology shows both fibroblast proliferation and myofibroblast differentiation. ${ }^{47}$ The former may result from several molecular events, such as stimulation of fibroblasts by growth factors or decreased apoptosis, possibly mediated by periostin signaling through the P13 kinase/Akt pathway. ${ }^{48}$ Excessive extracellular matrix deposition may be caused by an imbalance between matrix

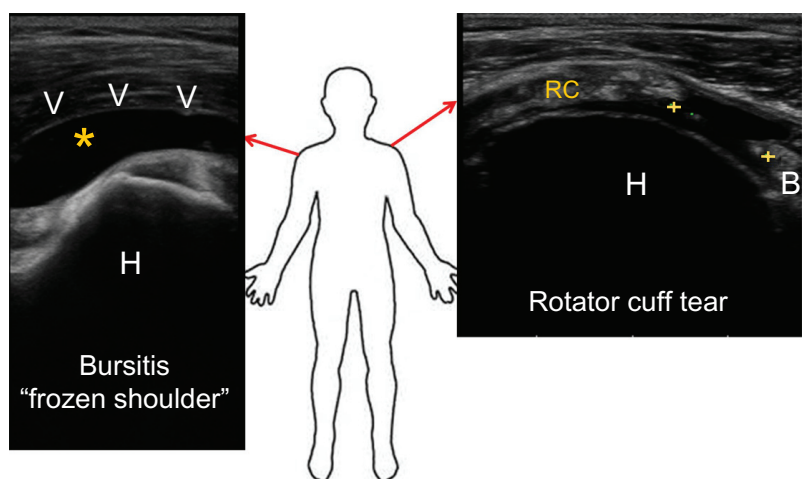

Figure I Typical ultrasound images of frozen shoulder and rotator cuff tear Notes: Frozen shoulder: A longitudinal scan at the upper third of the arm shows an effusion (*, anechoic) into the subacromial bursa with thickening of the linings (arrowheads). Rotator cuff tear: A transverse scan of rotator cuff shows a full defect in the insertional portion of tendon, from the bursal to the articular margin, filled with anechoic fluid (calipers).

Abbreviations: $\mathrm{H}$, humeral head; RC, rotator cuff tendon; $\mathrm{B}$, biceps.

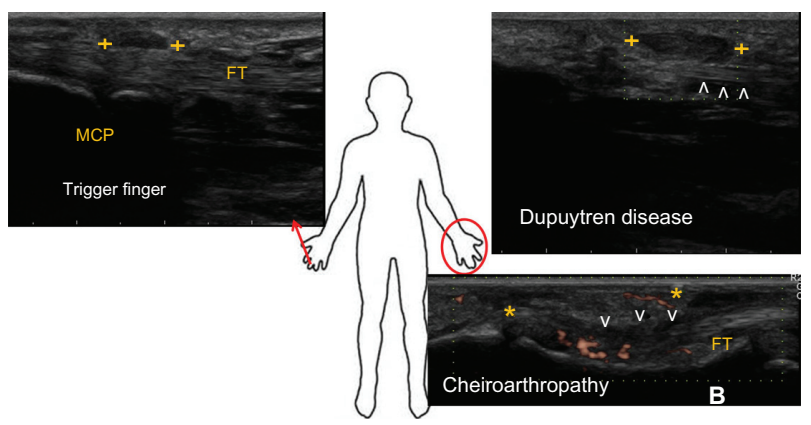

Figure 2 Examples of ultrasound appearances of tendon and fascia abnormalities in the hand.

Notes: Trigger finger: The longitudinal ultrasound scan shows a thickened hypoechoic pulley (calipers) over flexor tendons (FT) in correspondence of the metacarpophalangeal joints (MCP). Dupuytren disease: An hypoechoic nodule (calipers) is depicted over the palmar fasciae (arrowheads); neoangiogenesis is absent (longitudinal scan). Cherioarthropathy: A thickening of the flexor tendons (FT) (arrowheads) and of the subcutaneous tissue $\left(^{*}\right)$ of the finger with associated sign of neovascularization is shown (longitudinal scan).

Abbreviation: $\mathrm{B}$, bone.

metalloproteinases (MMPs) and their inhibitors (TIMPs), changes in ADAM12 (A disintegrin and metalloprotease), and dysregulation of proteoglycans and tenascin..$^{48}$ The possible role of oxidative stress, demonstrated by increased release of oxygen free radicals in affected palmar fascia is also being investigated. ${ }^{48}$

The etiology of Dupuytren's contracture remains unknown, although a strong contribution of genetics is supported by family history studies, higher rates in relatives of affected subjects, a high Caucasian prevalence, and high concordance rates in twin studies. Family history studies (comparing affected versus unaffected families) report a higher prevalence of two dihydrodiol dehydrogenase polymorphisms in subjects with a positive history of Dupuytren's contracture. ${ }^{49}$

In the search for genes differentially expressed using transcriptomics, 21 genes were found to be dysregulated. ${ }^{50}$ For example, three genes (THBS1, GADD $45 \alpha$, and NUAK1)

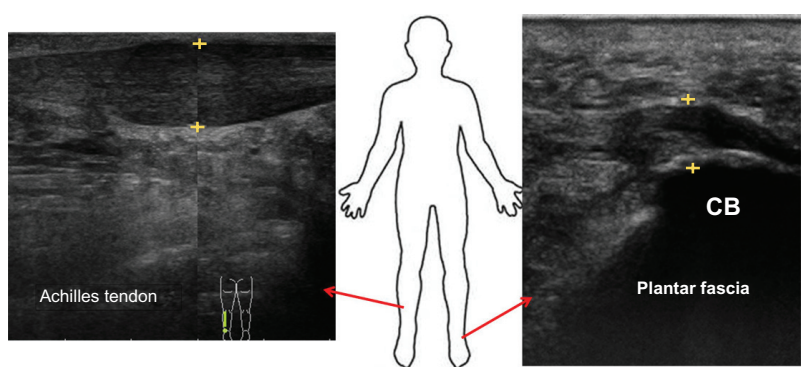

Figure 3 Sonographic appearance of common problems in the lower limb. Notes: Achilles tendon and Plantar fascia: The longitudinally scanned Achilles tendon and plantar fascia show a marked thickening of the midportion and of the insertional portion of plantar fascia, which also appears hypoechoic (calipers). Abbreviation: $\mathrm{CB}$, calcaneal bone. 
modulating the p38MAPK signaling pathway are presumed to be involved in uncontrolled proliferation of fibroblasts, which is a pathogenetic feature of Dupuytren's contracture. ${ }^{51}$ Further, upregulated expression of CCT-eta, a gene encoding for chaperonin, a protein involved in $\alpha$-smooth muscle actin folding, has been shown to modulate accumulation of $\alpha$-smooth muscle actin and contractility of myofibroblasts, and this represents a candidate biomarker that may further elucidate the pathophysiology of Dupuytren's contracture. ${ }^{52,53}$

Functional genomics provides a more complete picture of the molecular mechanisms involved in the pathogenesis of Dupuytren's contracture, allowing identification of new biomarkers and clues for discriminating several subtypes of the disease. ${ }^{48}$

The pathogenesis of cheiroarthropathy arises mainly from the damaging effects of hyperglycemia on collagen, which will be fully discussed below. A genetic component has been postulated, including microvascular abnormalities, which can lead to tissue hypoxia; this can result in the production of oxygen free radicals that, in turn, can lead to overproduction of growth factors and cytokines. ${ }^{28}$ The process is also fueled by changes in MMPs and their inhibitors, which are imbalanced in subjects with type 1 diabetic cheiroarthropathy. ${ }^{54}$

The pathogenesis of trigger finger has generally been ascribed to primary changes in the first annular ligament. On macroscopic observation, the tendons appear swollen, with loss of their natural glossy appearance, while histology shows microruptures and signs of degeneration. These microruptures generate overloading of adjacent fibers locally, while ruptured fibers remain unloaded. This mechanism influences both extracellular matrix repair and resorption, leading to a pathologic remodeling process. Moreover, significant changes in gene expression have been found. Collagen types I and III, aggrecan, and biglycan are all upregulated, whereas MMP-3 and TIMP-3 are downregulated. These changes in gene expression are similar to those found in Achilles tendinopathy, and support the hypothesis that trigger finger is a form of tendinosis. ${ }^{55}$

Overuse is recognized as the major pathogenetic factor for increased thickness of the Achilles tendon and plantar fasciitis in individuals with diabetes, along with subsequent limited range of motion at the ankle. Indeed, under normal exercise conditions, fibril stretching is followed by synthesis of extracellular matrix components and collagen neofibrils, as well as tendon hypertrophy. However, when repeated loading deviates from normal limits by differences in magnitude, frequency, duration, and direction, overuse injury may develop. Biochemical adaptation to these changes involves production of proinflammatory agents, such as interleukin-1 $\beta$, tumor necrosis factor- $\alpha$, prostaglandins, and enhanced production of MMPs, which cause matrix destruction. The pathogenetic cascade is extremely complex, and involves apoptosis of tenocyte, hypoxia, proliferation of neovessels, "smoldering" (disorganized) fibrillogenesis, disruption of collagen fibers, and hyaline and mucoid degeneration, usually without inflammation in the advanced stages. $^{56}$

\section{Role of diabetes}

These considerations highlight the relevance of different pathogenetic pathways in joint diseases associated with diabetes. However, it is evident that diabetes in itself may be a causative factor and able to amplify the damage induced by other agents. It is obvious that the complications of diabetes (such as diseases of the central or peripheral nervous systems, myopathy, renal insufficiency) may influence muscle strength and joint function, and can limit range of motion. For this reason, our considerations are limited to the deleterious influence of metabolic disorders on tendons and ligaments. According to an accepted hypothesis, the joint tissue damage in diabetes is caused by an excess of advanced glycation end products (AGEs) ${ }^{6}$ that form at a slow but constant rate, accumulating over time in the normal body. However, their formation is markedly accelerated in diabetes because of the increased availability of glucose. A key characteristic of reactive AGEs is the formation of covalent cross-links within collagen fibers, altering their structure and functionality.

Essentially, collagen cross-links can be generated via two different pathways, ie, the enzymatically driven, hydroxylysine-derived aldehyde pathway and the nonenzymatic glycation or oxidation-induced AGE crosslink. ${ }^{57-59}$ Independent of the beneficial effects on collagen strength conferred by enzymatic cross-links, cross-linking of AGEs is generally thought to cause deterioration of the biologic and mechanical function of tendons and ligaments. ${ }^{60}$ In fact, once formed, AGEs can be degraded only when the protein they are linked to is degraded. Therefore, the most extensive accumulation of AGEs occurs in tissues with low turnover, such as cartilage, bone, and tendon.

Other major features of AGEs relate to their interaction with a variety of AGE-binding receptors on the cell surface (ie, AGE-R1, AGE-R2, AGE-R3, and RAGE) ${ }^{61}$ Ligand engagement by AGE-binding receptors activates several critical molecular pathways and triggers a number of effects; these include pro-oxidant events via generation of reactive 
oxygen species and further proinflammatory events via $\mathrm{NF} \kappa \beta$ signaling. ${ }^{62}$ This accelerates cross-linking of AGE in collagen fibers, leading to sustained upregulation of proinflammatory mediators and a dysfunctional cell phenotype. ${ }^{63,64}$

Further negative effects of AGE include: modification of short-lived proteins, such as basic fibroblast growth factor, followed by a striking decrease in mitogenic activity; intracellular formation of AGE, leading to destruction of nitric oxide and impaired growth factor signaling; and enhanced apoptosis via oxidative stress, increased caspase activity, and extrinsic signaling through proapoptotic cytokines. ${ }^{65,66}$

In addition to the AGE-mediated pathogenetic mechanism, hyperglycemia in itself may lead to alterations in the redox environment, specifically in the polyol pathway, resulting in increased intracellular water and cellular edema. It has also been shown in porcine patellar tendons incubated with different glucose concentrations, that hyperglycemia produces a reduction in proteoglycans levels: this occurs in an AGE-independent manner, decreasing the synthesis or sulfation of glycosaminoglycans. ${ }^{67}$

It is not surprising that these metabolic abnormalities may be present in the early clinical stages of type 2 diabetes. ${ }^{44}$ Type 1 diabetes is diagnosed at an early stage because of a relatively acute clinical onset characterized by extreme elevations in glucose concentrations, whereas type 2 diabetes is usually diagnosed later in life, when many patients already have chronic complications. These subjects could definitely have had glucose intolerance or mild type 2 diabetes mellitus for a significant length of time before diabetes is diagnosed.

Finally, microvascular disease may contribute to tendon damage, leading to tissue hypoxia, overproduction of oxygen free radicals, and a permissive apoptotic environment. ${ }^{68}$ Microvascular disease presents with pervasive systemic effects, which can be seen in the tendons. The reduced neovascularization inside degenerative tendons, found with power Doppler sonography, ${ }^{69}$ is consistent with decreased levels of vascular endothelial growth factor, as well as reduced angiogenesis in experimental and clinical diabetic conditions. ${ }^{70-72}$

Recent advances in research on peroxisome proliferatoractivated receptor gamma (PPAR- $\gamma$ ) better explain the pathogenesis of diabetic tendinopathy. Downregulation of PPAR- $\gamma$ can limit vessel and nerve ingrowth, and can also affect neurogenesis, reducing neural progenitor cell recruitment, axonal outgrowth, neuronal survival, and proliferation of Schwann cells. ${ }^{73}$ The association between reduced nerve proliferation inside tendons and sensitive neuropathy reduces pain perception. Consequently, diabetic patients, who lack distress signals, may excessively exercise their tendons, making them prone to overuse damage.

Tendon damage develops via complex pathways. From this perspective, electron microscopic investigations show that collagen fibrils appear twisted, curved, overlapping, and otherwise highly disorganized. There is increased packing density of collagen fibrils, along with a decreased number of fibroblasts and tenocytes per unit of surface area. The reduction of elastic fibers is consistent. Finally, the number of capillaries per unit of surface area and arterial blood flow is reduced, particularly in elderly subjects. ${ }^{74}$ From a biomechanical point of view, several studies have demonstrated that collagen toughness, stiffness, and the elastic modulus are strongly influenced by formation of cross-links via AGE. ${ }^{75,76}$

As far as calcifications are concerned, it has been reported that calcium deposits are frequent in tendons of diabetic subjects, and are mainly found in the Achilles enthesis. The mechanisms of deposition of calcium salts are a subject of debate. In previous studies, necrosis of the tendon secondary to local ischemia, rupture of collagen fibers, and hyaline degeneration are recognized as the first step in promoting calcium deposition. ${ }^{77}$ According to recent research, calcifications can form because of erroneous differentiation of tendon stem/progenitor cells into chondrogenic and osteogenic cells, instead of tenocytes. Many morphogenetic proteins (osteopontin, decorin, aggrecan, biglycan, and fibromodulin) can be involved in ectopic chondrogenesis and subsequent ossification. ${ }^{78-80}$ However, the mechanism by which diabetes can predispose to and promote this abnormal differentiation is unknown. ${ }^{81}$

Given this complexity, it must be remembered that type 2 diabetes is frequently associated with being overweight, visceral adiposity, and other metabolic disorders, all of which are recognized as factors causing joint disease. Tendon damage in obese subjects is associated with two different mechanisms, ie, increased yield on load-bearing tendons and biochemical alterations attributed to systemic dysmetabolic factors. With increasing adiposity, weightbearing tendons are exposed to higher loads, which can lead to overuse tendinopathy.

Alternatively, the systemic hypothesis is based on studies showing that association with adiposity is equally strong for non-load-bearing and load-bearing tendons. ${ }^{82}$ Adipose tissue is now recognized as a major endocrine and signaling organ. In obese subjects, fatty tissue releases bioactive peptides and hormones, with the "adipokinome" including a range 
of proteins, such as chemerin, lipocalin 2, serum amyloid A3, leptin, and adiponectin. ${ }^{83}$ These proteins influence several activities in various mesenchymal cell phenotypes (tenocytes, chondrocytes, and osteocytes), which may directly modify tendon structure. In particular, adipokines are able to modulate cytokines and prostanoids, as well as production of MMPs. ${ }^{84,85}$ Consistently raised serum levels of prostaglandin E2, tumor necrosis factor- $\alpha$, and leukotriene B4 observed in obesity (and in subjects with impaired insulin sensitivity) provide further evidence that a systemic state of chronic, subclinical, low-grade inflammation is present in these conditions and may act as a prolonged disruptor of tendon homeostasis. ${ }^{86-89}$

Moreover, migration of immune cells (such as macrophages and mast cells) into adipose tissue is associated with a decrease in circulating levels of these cells. As a consequence, the release of profibrotic factors, such as tissue growth factor- $\beta$, is reduced, which may have a detrimental effect on tendon healing, especially if production of collagen types I and III is also reduced. ${ }^{90}$

Finally, the concurrent effect of advanced age in patients with type 2 diabetes mellitus must be considered. Aging tendons and ligaments are subjected to degenerative changes, whereby the number of tendon cells per unit of surface area is decreased, the tenocytes become slender, and there is reduced protein synthesis in the organelles, particularly in the rough endoplasmic reticulum. In extracellular medium, the collagen content decreases slightly, while levels of proteoglycans and glycoproteins decline more rapidly. The collagen bundles appear disintegrated and frayed, and a decreased number of elastic fibers is observed. As a result of these physiologic age-related changes, tendons and ligaments become weaker, and are more likely to tear or suffer from overuse injury. ${ }^{91}$

\section{Management}

\section{Targeted interventions}

There is firm evidence that the majority of diabetes-related joint diseases show a strong relationship with duration of disease, glucose levels, and age of the patient. ${ }^{14,92}$ Therefore, control of this metabolic disorder is critical. Knowledge of basic pathogenetic mechanisms of joint damage focuses on selective therapeutic interventions, along with drug use, which may counteract the detrimental effects of AGEs.

Several compounds are presently under study, and can be divided into inhibitors and breakers of AGE: the former inhibit formation of AGE, working as carbonyl-trapping agents and promote excretion or limit the uptake of iron and copper ions, while the latter include aminoguanidine, pyridoxamine, glucosamine, some angiotensin-converting enzyme inhibitors, aldose reductase inhibitors, genistein, and several natural derivatives (rutin, quercetin, hesperidin, and polyphenols), which cleave the cross-links made by AGE in tissue proteins, and have been effective in delaying a range of diabetic complications, including nephropathy, neuropathy, retinopathy, and vasculopathy in animal models of diabetes. ${ }^{93}$ Several have been investigated in clinical trials, but none have been approved as yet.

Recent studies highlight the relevance of isoforms of soluble RAGE (receptor for advanced glycation endproducts) in several diseases. Endogenous soluble RAGE isoforms have been found circulating in plasma and tissue. Their levels are lower in vascular diseases and diabetes, characterized by hyperactivity of ligand-RAGE, suggesting a significant inverse correlation with vascular damage. ${ }^{94,95}$ Impressive results obtained by administering recombinant soluble RAGE in animal models suggest that they may neutralize ligandmediated damage by acting as a decoy and blocking diabetic complications and joint inflammation. ${ }^{96}$ It is anticipated that new pharmacologic compounds which counteract the negative effects of AGEs may be part of future clinical trials and then progress to clinical practice, resulting in greater control of AGE-related complications, including tendon and ligament damage.

\section{Specific treatments}

Several techniques have been introduced, often empirically, for the treatment of tendon and joint diseases. The mechanism of action of some therapies has been supported by sound experimental data, but for others it remains generic and unclear.

Subtle, low-grade, persistent inflammation is often considered to be a pathogenetic factor in several joint diseases and their relapses, so anti-inflammatory drugs and corticosteroids are frequently used with good short-term results. The mode of action and adverse effects of these agents have been studied, with risk of infection, local calcification, and skin atrophy with depigmentation (mainly on repeated administration) having been reported. Systemic effects may also occur, but only when large amount of steroids are administered. Weakened mechanical properties of tendons and ligaments may be another consequence, probably due to their propensity to inhibit formation of connective tissue. Therefore, short-term gains must be weighed against potential side effects, including symptomatic relief versus complete functional recovery. ${ }^{97,98}$

Intra-articular injection of hyaluronan derivatives also provides therapeutic benefit for articular function. 
Hyaluronic acid seems to restore the elastic and viscous properties of synovial fluid, acting as a shock absorber to improve tissue elasticity and gliding of anatomical structures. Other mechanisms are anti-inflammatory and antinociceptive activity, normalization of hyaluronan synthesis, and inhibition of degradation of hyaluronic acid. ${ }^{99}$ Table $4^{100-103}$ shows specific treatment modalities and their putative mechanisms.

\section{Therapeutic results in diabetes- related joint disease}

The aforementioned treatments have been used, alone or in combination, for diabetes-related joint disease, with inconclusive and sometimes conflicting results. Although there are many descriptive studies, randomized clinical trials specifically addressing diabetic patients are lacking. Moreover, few studies have compared different therapies, or the efficacy of selected therapies versus placebo. The presence of bias, such as insufficient power, inappropriate statistics, open study designs, short duration of follow-up, significant population diversity for interventions and outcome measures, as well as varied patient characteristics in different phases of the disease, preclude any firm conclusions.

\section{Frozen shoulder}

A recent systematic review identified a statistically significant short-term benefit using short-wave diathermy or laser therapy compared with home exercise alone. ${ }^{104}$ Another study found marginally significant improvements in function and disability, including improvement in range of motion, using highgrade mobilization compared with low-grade mobilization.
Three studies comparing acupuncture with another promising treatment did not reach a conclusion about the effectiveness of acupuncture for primary frozen shoulder. ${ }^{105}$ Based on one single quality study, there was no evidence that manipulation under anesthesia was better than conservative intervention involving physical therapy advice in two sessions, plus written instructions for a daily training program. ${ }^{106}$

Hyaluronic acid has also been shown to be unsatisfactory, and there is insufficient evidence to recommend this treatment in preference to steroid or physical therapy. ${ }^{97}$ The effects of steroid injections have been widely investigated, but with conflicting results. ${ }^{107}$ For pain, there was a statistically significant short-term benefit (up to 3 months) in comparison with home exercise alone, although this did not occur with 4 weeks of physiotherapy. However, when steroid injections were provided in conjunction with physiotherapy, there was an added benefit for pain, function (improved range of motion), and disability over physical therapy and steroid injection. ${ }^{108}$ Finally, only case series are available for capsular release. ${ }^{109}$ A significant improvement in several outcomes based on an average length of follow-up of 10 (range 3-29) months was found, but the lack of a control group makes it difficult to assess the effectiveness of an intervention in a condition such as frozen shoulder, which is likely to resolve spontaneously over about three years. No differences in outcome between diabetic and nondiabetic shoulder have been observed.

\section{Trigger finger}

Percutaneous release, by open surgery or corticosteroid injection, is the most common treatment for trigger finger. ${ }^{110-113}$

Table 4 Aspecific treatment modalities of diabetes-related diseases

Treatment modalities

Rehabilitation (different stimulus as well as types and frequency of loading)

Manual techniques (friction massage, augmented soft tissue mobilization, myofascial release, active release technique)

Acupunture

Heating

Electrical stimulation (direct, alternating or pulsing, or combined in different ways)

Extracorporeal shock wave

Low-intensity "cold" lasers

Surgery (last option, after exhausting conservative management)

\section{Putative mechanisms of action}

Mechanical (improved joint motion) and biochemical effects (collagen synthesis, mediators release)

Break adhesions around joint structures, decrease spasms and edema, increase ROM, recovery of neuromuscular control

Target the nervous system inducing biophysical signals to allow for healing responses to occur

Increase tissue extensibility prior to stretch, decrease pain, increase blood flow to the diseased area

Increase cell metabolism and local blood flow, control pain, inhibit spasticity

Improved blood supply, increased cell proliferation, disintegrations of calcifications

Stimulation of the production of collagen and cellular metabolism Excision of fibrotic adhesions, remove nodules and areas of degeneration, restore vascularity possibly estimulating the tissue biochemical machinery Reconstruction procedures sometimes required

Abbreviation: ROM, range of movement. 
Corticosteroid injections are recommended as first-line therapy, have a high efficacy rate $(50 \%-60 \%)$, and are more effective for the thumb than for the other fingers (92\% versus $50 \%-57 \%$, respectively). ${ }^{114}$ This could be due to anatomic differences in the flexor tendon pulley system or to more accurate steroid injection under ultrasound guidance. Unfortunately, injections are associated with a relapse rate of $33 \%$ within one year. In clinical practice, patients can receive a second steroid injection when there has been no benefit from the first or when symptoms deteriorate; however, there is no documented evidence of its effectiveness.

Surgery remains the definitive treatment when conservative therapy has failed. Open trigger surgery is the standard technique, and traditionally consists of A1 pulley release in which the pulley is completely dissected. Alternatively, percutaneous release performed with different techniques (hypodermic needle, a tenotome blade, and specially designed knives and needle-knives) may offer advantages in terms of operative time and expense. A recent meta-analysis reports that patients treated with percutaneous methods have fewer failures (relative risk, 0.07 ; 95\% confidence interval $0.02-0.21$ ) and greater satisfaction levels (relative risk, 2.01; 95\% confidence interval 1.62-2.48) than those who received corticosteroid injections. ${ }^{114}$

A disadvantage of these techniques is limited visibility, potentially resulting in damage to nerves and/or tendons. However, a meta-analysis comparing randomized controlled trials using the two methods shows that open surgery is similar to percutaneous release in terms of failure rate and frequency of complications, including infections, nerve injury, tendon laceration, and longstanding pain, with contracture in about $20 \%$ of cases. ${ }^{110}$

There is further evidence that trigger finger in diabetic patients is more difficult to treat and more likely to develop triggering in other digits; this might require open surgery, which is also more likely to fail. In conclusion, the guidelines suggest that two steroid injections followed by surgery is the most cost-effective procedure.

\section{Cheiroarthropathy}

The specific treatment of diabetic cheiroarthropathy, other than by optimizing glycemic control, is unknown. ${ }^{115}$ Symptomatic therapy includes pain relievers, antiinflammatory drugs, corticosteroid injections, and stretching exercises, but these are often unsatisfactory. In severe cases, surgery can improve both sensation and discomfort, although some problems may remain.

\section{Dupuytren's contracture}

Conventional treatment for Dupuytren's contracture, ie, surgical excision of the affected tissue, is recommended in patients with functional impairment and contractures of 30 degrees or more. Damage to digital nerves, blood vessels, and underlying flexor tendons, as well as the possibility of skin necrosis, are substantial risks associated with surgery. Further, recurrence rates are very high. Nonsurgical treatment options, including corticosteroid injections, applications of vitamin A and E, radiotherapy, ultrasound therapy, and gamma interferon injections, have been unsatisfactory.

Recently, an injectable formulation of collagenase from Clostridium histolyticum has been approved as an option for the treatment of advanced Dupuytren's contracture. Using this office-based, minimally invasive technique, collagenase can be injected to lyse collagen and disrupt the contracted tendon cords. The next day, the treated joint is manipulated in an attempt to rupture the cord.

In a prospective, randomized, double-blind, placebocontrolled, Phase III clinical trial, Hurst et $\mathrm{al}^{116}$ reported that $1-3$ intralesional injections of collagenase $(0.58 \mathrm{mg}$ per injection) significantly reduced contractures and also improved range of motion in joints affected by advanced Dupuytren's contracture. Serious treatment-related adverse events (tendon rupture and complex regional pain syndrome) were reported in a few cases.

\section{Conclusion}

Frozen shoulder, rotator cuff tears, cheiroarthropathy, and Dupuytren's contracture involve joints, tendons, and ligament diseases, which are strictly related to a diabetic condition. As a consequence, joint mobility is reduced, with functional limitation, leading to impaired ability to perform activities of daily living. Complex pathogenetic mechanisms are involved in these diseases. Diabetes is a concomitant factor in terms of promoting and aggravating anatomic and functional damage, mainly due to increased formation of AGEs. Overweight and advanced age are frequently associated with type 2 diabetes, which further increases the risk for these patients. ${ }^{117}$ Elderly people are a growing segment of the population in western countries, and non-insulin-dependent type 2 diabetes mellitus is an age-related disease. Therefore, limited joint motion must be regarded as a fundamental public health problem. Some joint diseases, especially cheiroarthropathy, are often precursors of chronic diabetic complications.

Prevention and strict control of this metabolic disorder is essential, because it has been demonstrated that limited joint motion is related to duration of disease and hyperglycemia. 
Several treatments are used in clinical practice, but their mechanisms of action are not completely understood, and debate continues about their efficacy.

The dilemma facing doctors in the current evidencebased climate is how to link clinical experience with clinical research. Use of specific treatments (including optimal duration, amount, timing of administration, and intensity) must be based on both clinical observation and experience, while evaluating functional outcomes and quality of life.

\section{Disclosure}

The authors report no conflicts of interest in this work.

\section{References}

1. Rosenbloom AL, Silverstein JH. Connective tissue and joint disease in diabetes mellitus. Endocrinol Metab Clin North Am. 1996;25:473-483.

2. Smith LL, Burnet SP, McNeil JD. Musculoskeletal manifestations of diabetes mellitus. Br J Sports Med. 2003;37:30-35.

3. Lebiedz-Odrobina D, Kay J. Rheumatic manifestations of diabetes mellitus. Rheum Dis Clin North Am. 2010;36:681-699.

4. Sanya AO, Obi CS. Range of motion in selected joints of diabetic and non-diabetic subjects. Afr J Health Sci. 1999;6:17-21.

5. Shinabarger NI. Limited joint mobility in adults with diabetes mellitus. Phys Ther. 1987;67:215-218.

6. Abate M, Schiavone C, Pelotti P, Salini V. Limited joint mobility in diabetes and ageing: recent advances in pathogenesis and therapy. Int J Immunopathol Pharmacol. 2010;23:997-1003.

7. Balci N, Balci MK, Tüzüner S. Shoulder adhesive capsulitis and shoulder range of motion in type II diabetes mellitus: association with diabetic complications. J Diabetes Complications. 1999;13:135-140.

8. Garcilazo C, Cavallasca JA, Musuruana JL. Shoulder manifestations of diabetes mellitus. Curr Diabetes Rev. 2010;6:334-340.

9. Pal B, Anderson J, Dick WC, Griffiths ID. Limitation of joint mobility and shoulder capsulitis in insulin- and non-insulin-dependent diabetes mellitus. Br J Rheumatol. 1986;25:147-151.

10. Thomas SJ, McDougall C, Brown ID, et al. Prevalence of symptoms and signs of shoulder problems in people with diabetes mellitus. J Shoulder Elbow Surg. 2007;16:748-751.

11. Milgrom C, Novack V, Weil Y, Jaber S, Radeva-Petrova DR, Finestone A. Risk factors for idiopathic frozen shoulder. Isr Med Assoc J. 2008;10:361-364.

12. Mavrikakis ME, Drimis S, Kontoyannis DA. Calcific shoulder periarthritis (tendinitis) in adult onset diabetes mellitus: a controlled study. Ann Rheum Dis. 1989;48:211-214.

13. Arkkila PE, Kantola IM, Viikari JS, Rönnemaa T. Shoulder capsulitis in type I and II diabetic patients: association with diabetic complications and related diseases. Ann Rheum Dis. 1996;55:907-914.

14. Ramchurn N, Mashamba C, Leitch E, et al. Upper limb musculoskeletal abnormalities and poor metabolic control in diabetes. Eur J Intern Med. 2009;20:718-721.

15. Yian EH, Contreras R, Sodl JF. Effects of glycemic control on prevalence of diabetic frozen shoulder. J Bone Joint Surg Am. 2012;94:919-923.

16. Yamamoto A, Takagishi K, Osawa T, et al. Prevalence and risk factors of a rotator cuff tear in the general population. J Shoulder Elbow Surg. 2010;19:116-120.

17. Abate M, Schiavone C, Salini V. Sonographic evaluation of the shoulder in asymptomatic elderly subjects with diabetes. BMC Musculoskelet Disord. 2010;11:278.

18. Ko JY, Wang FS. Rotator cuff lesions with shoulder stiffness: updated pathomechanisms and management. Chang Gung Med J. 2011;34:331-340.
19. Milgrom C, Schaffler M, Gilbert S, van Holsbeeck M. Rotator-cuff changes in asymptomatic adults. The effect of age, hand dominance and gender. J Bone Joint Surg Br. 1995;77:296-298.

20. Schibany N, Zehetgruber H, Kainberger F, et al. Rotator cuff tears in asymptomatic individuals: a clinical and ultrasonographic screening study. Eur J Radiol. 2004;51:263-268.

21. Moosmayer S, Smith HJ, Tariq R, Larmo A. Prevalence and characteristics of asymptomatic tears of the rotator cuff: an ultrasonographic and clinical study. J Bone Joint Surg Br. 2009;91:196-200.

22. Clement ND, Hallett A, MacDonald D, Howie C, McBirnie J. Does diabetes affect outcome after arthroscopic repair of the rotator cuff? J Bone Joint Surg Br. 2010;92:1112-1117.

23. Namdari S, Green A. Range of motion limitation after rotator cuff repair. J Shoulder Elbow Surg. 2010;19:290-296.

24. Lundbaek K. Stiff hands in long-term diabetes. Acta Med Scand. 1957; 158:447-451.

25. Rosenbloom AL, Frias JL. Diabetes mellitus, short stature and joint stiffness: a new syndrome. Clin Res. 1974;22:92A.

26. Savas S, Koroglu BK, Koyuncuoglu HR, Uzar E, Celik H, Tamer NM. The effects of the diabetes related soft tissue hand lesions and the reduced hand strength on functional disability of hand in type 2 diabetic patients. Diabetes Res Clin Pract. 2007;77:77-83.

27. Aydeniz A, Gursoy S, Guney E. Which musculoskeletal complications are most frequently seen in type 2 diabetes mellitus? J Int Med Res. 2008;36:505-511.

28. Papanas N, Maltezos E. The diabetic hand: a forgotten complication? J Diabetes Complications. 2010;24:154-162.

29. Fisher L, Kurtz A, Shipley M. Association between cheiroarthropathy and frozen shoulder in patients with insulin-dependent diabetes mellitus. Br J Rheumatol. 1986;25:141-146.

30. Serban AL, Udrea GF. Rheumatic manifestations in diabetic patients. J Med Life. 2012;5:252-257.

31. Amin R, Bahu TK, Widmer B, Dalton RN, Dunger DB. Longitudinal relation between limited joint mobility, height, insulin-like growth factor 1 levels, and risk of developing microalbuminuria: the Oxford Regional Prospective Study. Arch Dis Child. 2005;90:1039-1044.

32. Crispin JC, Alcocer-Varela J. Rheumatologic manifestations of diabetes mellitus. Am J Med. 2003;114:753-757.

33. Childs SG. Dupuytren's disease. Orthop Nurs. 2005;24:160-164.

34. Gudmundsson KG, Arngrímsson R, Sigfússon N, Björnsson A, Jónsson T. Epidemiology of Dupuytren's disease: clinical, serological, and social assessment. The Reykjavik Study. Clin Epidemiol. 2000;53: 291-296.

35. Arkkila PE, Gautier JF. Musculoskeletal disorders in diabetes mellitus: an update. Best Pract Res Clin Rheum. 2003;17:945-970.

36. Wiwanitkit S, Wiwanitkit V. Trigger digits and diabetes mellitus. NAm J Med Sci. 2012;4:117-119.

37. Cagliero E, Apruzzese W, Perlmutter GS. Skeletal disorders of the hand and shoulder in patients with diabetes mellitus. Am J Med. 2002;112: 487-490.

38. Chammas M, Bousquet P, Renard E. Dupuytren's disease, carpal tunnel syndrome, trigger finger, and diabetes mellitus. J Hand Surg Am. 1995;20:109-114.

39. Duffin AC, Lam A, Kidd R, Chan AK, Donaghue KC. Ultrasonography of plantar soft tissues thickness in young people with diabetes. Diabet Med. 2002;19:1009-1113.

40. Bolton NR, Smith KE, Pilgram TK, Mueller MJ, Bae KT. Computed tomography to visualize and quantify the plantar aponeurosis and flexor hallucis longus tendon in the diabetic foot. Clin Biomech (Bristol, Avon). 2005;20:540-546.

41. Akturk M, Ozdemir A, Maral I, Yetkin I, Arslan M. Evaluation of Achilles tendon thickening in type 2 diabetes mellitus. Exp Clin Endocrinol Diabetes. 2007;115:92-96.

42. Giacomozzi C, D’Ambrogi E, Uccioli L, Macellari V. Does the thickening of Achilles tendon and plantar fascia contribute to the alteration of diabetic foot loading? Clin Biomech (Bristol, Avon). 2005; 20:532-539. 
43. Papanas N, Courcoutsakis N, Papatheodorou K, Daskalogiannakis G, Maltezos E, Prassopoulos P. Achilles tendon volume in type 2 diabetic patients with or without peripheral neuropathy: MRI study. Exp Clin Endocrinol Diabetes. 2009;117:645-648.

44. Abate M, Schiavone C, Di Carlo L, Salini V. Achilles tendon and plantar fascia in recently diagnosed type II diabetes: role of body mass index. Clin Rheumatol. 2012;31:1109-1113.

45. Batista F, Nery C, Pinzur M, et al. Achilles tendinopathy in diabetes mellitus. Foot Ankle Int. 2008;29:498-501.

46. Kabbabe B, Ramkumar S, Richardson M. Cytogenetic analysis of the pathology of frozen shoulder. Int J Shoulder Surg. 2010;4:75-78.

47. Hinz B. Formation and function of the myofibroblast during tissue repair. J Invest Dermatol. 2007;127:526-537.

48. Sedic M, Pavelic SK, Hock K. Using functional genomics to identify drug targets: a Dupuytren's disease example. Methods Mol Biol. 2012; 910:15-31.

49. Zyluk A, Debniak T, Puchalski P. Common variants of the ALDH2 and DHDH genes and the risk of Dupuytren's disease. J Hand Surg Eur Vol. January 8, 2013. [Epub ahead of print.]

50. Shih B, Watson S, Bayat A. Whole genome and global expression profiling of Dupuytren's disease: systematic review of current findings and future perspectives. Ann Rheum Dis. 2012;71:1440-1447.

51. Ratkaj I, Bujak M, Jurišić D, et al. Microarray analysis of Dupuytren's disease cells: the profibrogenic role of the TGF- $\beta$ inducible p38 MAPK pathway. Cell Physiol Biochem. 2012;30:927-942.

52. Satish L, O'Gorman DB, Johnson S, et al. Increased CCT-eta expression is a marker of latent and active disease and a modulator of fibroblast contractility in Dupuytren's contracture. Cell Stress Chaperones. January 6, 2013. [Epub ahead of print.]

53. Satish L, Lo N, Gallo PH, Johnson S, Haberman S, Kathju S. Chaperonin containing T-complex polypeptide (CCT) subunit expression in oral mucosal wounds and fibroblasts. Cell Stress Chaperones. 2011;16: 675-680.

54. Kaminska-Winciorek G, Deja G, Polanska J, Jarosz-Chobot P. The role of selected metalloproteinases in cheiroarthropathy in children with type 1 diabetes - a pilotage study. Int J Clin Pract. 2012;66:374-377.

55. Lundin AC, Aspenberg P, Eliasson P. Trigger finger, tendinosis, and intratendinous gene expression. Scand J Med Sci Sports. August 12, 2012. [Epub ahead of print.]

56. Abate M, Silbernagel KG, Siljeholm C, et al. Pathogenesis of tendinopathies: inflammation or degeneration? Arthritis Res Ther. 2009;11:235.

57. Fujii K, Yamagishi T, Nagafuchi T, Tsuji M, Kuboki Y. Biochemical properties of collagen from ligaments and periarticular tendons of the human knee. Knee Surg Sports Traumatol Arthrosc. 1994;2: 229-233.

58. Eyre DR, Paz MA, Gallop PM. Cross-linking in collagen and elastin. Аnпи Rev Biochem. 1984;53:717-748.

59. Saito M, Marumo K. Collagen cross-links as a determinant of bone quality: a possible explanation for bone fragility in aging, osteoporosis, and diabetes mellitus. Osteoporos Int. 2010;21:195-214.

60. DeGroot J. The AGE of the matrix: chemistry, consequence and cure. Curr Opin Pharmacol. 2004;4:301-305.

61. Vazzana N, Santilli F, Cuccurullo C, Davì G. Soluble forms of RAGE in internal medicine. Intern Emerg Med. 2009;4:389-401.

62. Franke S, Sommer M, Rüster C, et al. Advanced glycation end products induce cell cycle arrest and proinflammatory changes in osteoarthritic fibroblast-like synovial cells. Arthritis Res Ther. 2009;11:R136.

63. Goldin A, Beckman JA, Schmidt AM, Creager MA. Advanced glycation end products: sparking the development of diabetic vascular injury. Circulation. 2006;114:597-605.

64. Steenvoorden MM, Toes RE, Ronday HK, Huizinga TW, Degroot J. RAGE activation induces invasiveness of RA fibroblast-like synoviocytes in vitro. Clin Exp Rheumatol. 2007;25:740-742.

65. Huijberts MS, Schaper NC, Schalkwijk CG. Advanced glycation end products and diabetic foot disease. Diabetes Metab Res Rev. 2008;24 Suppl 1:S19-S24.
66. Alikhani Z, Alikhani M, Boyd CM, Nagao K, Trackman PC, Graves DT. Advanced glycation end products enhance expression of pro-apoptotic genes and stimulate fibroblast apoptosis through cytoplasmic and mitochondrial pathways. J Biol Chem. 2005;280:12087-12095.

67. Burner T, Gohr C, Mitton-Fitzgerald E, Rosenthal AK. Hyperglycemia reduces proteoglycan levels in tendons. Connect Tissue Res. 2012;53: 535-541.

68. Franco R, Sánchez-Olea R, Reyes-Reyes EM, Panayiotidis MI. Environmental toxicity, oxidative stress and apoptosis: ménage à trois. Mutat Res. 2009;674:3-22.

69. Abate M, Schiavone C, Salini V. Neoangiogenesis is reduced in chronic tendinopathies of type 2 diabetic patients. Int J Immunopathol Pharmacol. 2012;25:757-761.

70. Abaci A, Oğuzhan A, Kahraman S, et al. Effect of diabetes mellitus on formation of coronary collateral vessels. Circulation. 1999;99:2239-2234.

71. Waltenberger J. Impaired collateral vessel development in diabetes: potential cellular mechanisms and therapeutic implications. Cardiovasc Res. 2001:49:554-560.

72. Shoji T, Koyama H, Morioka T, et al. Receptor for advanced glycation end products is involved in impaired angiogenic response in diabetes. Diabetes. 2006;55:2245-2255.

73. Wang SH, Sun ZL, Guo YJ, Yuan Y, Li L. PPARgamma-mediated advanced glycation end products regulation of neural stem cells. Mol Cell Endocrinol. 2009;307:176-184.

74. Grant WP, Sullivan R, Sonenshine DE, et al. Electron microscopic investigation of the effects of diabetes mellitus on the Achilles tendon. J Foot Ankle Surg. 1997;36:272-278.

75. Jeswani T, Morlese J, McNally EG. Getting to the heel of the problem: plantar fascia lesions. Clin Radiol. 2009;64:931-939.

76. Reddy GK. Cross-linking in collagen by nonenzymatic glycation increases the matrix stiffness in rabbit Achilles tendon. Exp Diabesity Res. 2004;5:143-153.

77. Oliva F, Giai Via A, Maffulli N. Physiopathology of intratendinous calcific deposition. BMC Med. 2012;10:95.

78. Rui YF, Lui PP, Chan LS, Chan KM, Fu SC, Li G. Does erroneous differentiation of tendon-derived stem cells contribute to the pathogenesis of calcifying tendinopathy? Chin Med J (Engl). 2011;124:606-610.

79. Zhang J, Wang JH. BMP-2 mediates PGE(2)-induced reduction of proliferation and osteogenic differentiation of human tendon stem cells. J Orthop Res. 2012;30:47-52.

80. Oliva F, Barisani D, Grasso A, Maffulli N. Gene expression analysis in calcific tendinopathy of the rotator cuff. Eur Cell Mater. 2011;21: 548-557.

81. Maffulli N, Reaper J, Ewen SW, Waterston SW, Barrass V. Chondral metaplasia in calcific insertional tendinopathy of the Achilles tendon. Clin J Sport Med. 2006;16:329-334.

82. Gaida JE, Alfredson H, Kiss ZS, Bass SL, Cook JL. Asymptomatic Achilles tendon pathology is associated with a central fat distribution in men and a peripheral fat distribution in women: a cross sectional study of 298 individuals. BMC Musculoskelet Disord. 2010;11:41.

83. Conde J, Gomez R, Bianco G, et al. Expanding the adipokine network in cartilage: identification and regulation of novel factors in human and murine chondrocytes. Ann Rheum Dis. 2011;70:551-559.

84. Lago R, Gomez R, Otero M, et al. A new player in cartilage homeostasis: adiponectin induces nitric oxide synthase type II and pro-inflammatory cytokines in chondrocytes. Osteoarthritis Cartilage. 2008;16: 1101-1109.

85. Berry PA, Jones SW, Cicuttini FM, Wluka AE, Maciewicz RA. Temporal relationship between serum adipokines, biomarkers of bone and cartilage turnover, and cartilage volume loss in a population with clinical knee osteoarthritis. Arthritis Rheum. 2011;63:700-707.

86. Cilli F, Khan M, Fu F, Wang JH. Prostaglandin E2 affects proliferation and collagen synthesis by human patellar tendon fibroblasts. Clin J Sport Med. 2004;14:232-236.

87. Cook JL, Purdam CR. Is tendon pathology a continuum? A pathology model to explain the clinical presentation of load-induced tendinopathy. Br J Sports Med. 2009;43:409-416. 
88. Maffulli N, Longo UG, Loppini M, Denaro V. Current treatment options for tendinopathy. Expert Opin Pharmacother. 2010;11:2177-2186.

89. Battery L, Maffulli N. Inflammation in overuse tendon injuries. Sports Med Arthrosc. 2011;19:213-217.

90. Scott A, Lian R, Bahr R, Hart DA, Duronio V, Khan KM. Increased mast cell numbers in human patellar tendinosis: correlation with symptom duration and vascular hyperplasia. Br J Sports Med. 2008;42: $753-757$.

91. Narici MV, Maffulli N, Maganaris CN. Ageing of human muscles and tendons. Disabil Rehabil. 2008;30:1548-1554.

92. Vance MC, Tucker JJ, Harness NG. The association of hemoglobin Alc with the prevalence of stenosing flexor tenosynovitis. $J$ Hand Surg Am. 2012;37:1765-1769.

93. Thornalley PJ. Use of aminoguanidine (pimagedine) to prevent the formation of advanced glycation endproducts. Arch Biochem Biophys. 2003;419:31-40.

94. Catalano M, Cortelazzo A, Santi R, et al. The Pro12 Ala polymorphism of peroxisome proliferator-activated receptor-gamma2 gene is associated with plasma levels of soluble RAGE (receptor for advanced glycation endproducts) and the presence of peripheral arterial disease. Clin Biochem. 2008;41:981-985.

95. Katakami N, Matsuhisa M, Kaneto H, et al. Serum endogenous secretory RAGE level is an independent risk factor for the progression of carotid atherosclerosis in type 1 diabetes. Atherosclerosis. 2009;204: 288-292.

96. Hudson BI, Bucciarelli LG, Wendt T, et al. Blockade of receptor for advanced glycation endproducts: a new target for therapeutic intervention in diabetic complications and inflammatory disorders. Arch Biochem Biophys. 2003;419:80-88.

97. Salini V, Abate M. Percutaneous steroidal treatment in relapses of chronic tendinopathies: a pilot study. Int J Immunopathol Pharmacol. 2011;24:211-216.

98. Hartung W, Ehrenstein B, Härle P, Fleck M, Weigand T. Ultrasoundguided joint injections in patients with rheumatic diseases. Z Rheumatol. 2011;70:455-461. German.

99. Abate M, Pulcini D, Di Iorio A, Schiavone C. Viscosupplementation with intra-articular hyaluronic acid for treatment of osteoarthritis in the elderly. Curr Pharm Des. 2010;16:631-640.

100. Cameron-Smith D. Exercise and skeletal muscle gene expression. Clin Exp Pharmacol Physiol. 2002;29:209-213.

101. Arnold I, Guttke T. Physical therapy as part of a complex orthopedic rheumatology approach. Physiotherapy, cryotherapy, extracorporeal shockwave lithotripsy, local intra-articular joint injections. Orthopade 2012;41:520-525. German.
102. Harvey L, Herbert R, Crosbie J. Does stretching induce lasting increases in joint ROM? A systematic review. Physiother Res Int. 2002;7:1-13.

103. Rivenburgh DW. Physical modalities in the treatment of tendon injuries. Clin Sports Med. 1992;11:645-659.

104. Maund E, Craig D, Suekarran S, et al. Management of frozen shoulder: a systematic review and cost-effectiveness analysis. Health Technol Assess. 2012;16:1-264.

105. Green S, Buchbinder R, Hetrick SE. Acupuncture for shoulder pain. Cochrane Database Syst Rev. 2005;2:CD005319.

106. Rookmoneea M, Dennis L, Brealey S, et al. The effectiveness of interventions in the management of patients with primary frozen shoulder. J Bone Joint Surg Br. 2010;92B:1267-1272.

107. Shah N, Lewis M. Shoulder adhesive capsulitis: systematic review of randomised trials using multiple corticosteroid injections. $\mathrm{Br} \mathrm{J} \mathrm{Gen}$ Pract. 2007;57:662-667.

108. Green S, Buchbinder R, Hetrick SE. Physiotherapy interventions for shoulder pain. Cochrane Database Syst Rev. 2003;2:CD004258.

109. Buchbinder R, Green S, Youd JM, Johnston Renea V, Cumpston M. Arthrographic distension for adhesive capsulitis (frozen shoulder). Cochrane Database Syst Rev. 2008;1:CD007005.

110. Dala-Ali BM, Nakhdjevani A, Lloyd MA, Schreuder FB. The efficacy of steroid injection in the treatment of trigger finger. Clin Orthop Surg. 2012;4:263-268.

111. Hamano H, Motomiya M, Iwasaki N. Adverse effect of repeated corticosteroid injections for trigger finger on flexor pulley system. J Hand Surg Eur Vol. October 25, 2012. [Epub ahead of print.]

112. Shah AS, Bae DS. Management of pediatric trigger thumb and trigger finger. J Am Acad Orthop Surg. 2012;20:206-213.

113. Wang $\mathrm{H}$, Zeng $\mathrm{H}, \mathrm{Wu} \mathrm{H}$, Shen Q, Cai C, Chen W. Percutaneous release of trigger finger with $\mathrm{L}$ shaped hollow needle knife. Zhongguo Xiu Fu Chong Jian Wai Ke Za Zhi. 2012;26:14-16. Chinese.

114. Wang J, Zhao JG, Liang CC. Percutaneous release, open surgery, or corticosteroid injection, which is the best treatment method for trigger digits? Clin Orthop Relat Res. December 4, 2012. [Epub ahead of print.]

115. Hider SL, Roy DK, Augustine T, Parrott N, Bruce IN. Resolution of diabetic cherioarthropathy after pancreatic transplantation. Diabetes Care. 2004;27:2279-2280.

116. Hurst LC, Badalamente M, Hentz VR, et al. Injectable collagenase clostridium histolyticum for Dupuytren's contracture. $N$ Eng $J$ Med. 2009;361:968-979.

117. Tuite DJ, Renström PA, O'Brien M. The aging tendon. Scand J Med Sci Sports. 1997;7:72-77.

Diabetes, Metabolic Syndrome and Obesity: Targets and Therapy

Dovepress

\section{Publish your work in this journal}

Diabetes, Metabolic Syndrome and Obesity: Targets and Therapy is an international, peer-reviewed open-access journal committed to the rapid publication of the latest laboratory and clinical findings in the fields of diabetes, metabolic syndrome and obesity research Original research, review, case reports, hypothesis formation, expert opinion and commentaries are all considered for publication. The manuscript management system is completely online and includes a very quick and fair peer-review system, which is all easy to use. Visit http://www.dovepress.com/testimonials.php to read real quotes from published authors. 